Jiang, K. \& Hyland, K. (2020). "There are significant differences...": the secret life of existential there in academic writing. Lingua.

\title{
"There are significant differences...": the secret life of existential there in academic writing
}

\author{
Feng (Kevin) Jiang and Ken Hyland
}

\begin{abstract}
While numerous interactive aspects of academic writing have attracted attention in recent years, one common feature which has escaped scrutiny is "existential there" (as in "there are significant differences"). Based on a corpus of 80 research articles from four disciplines, this study explores the 'secret life' of this construction, revealing how academic writers use it to organise their arguments and persuade peers of their claims. In contrast to the style guides which regard existential there as an "empty structure" to be avoided, our data show that academic authors make considerable use of it across different sections of the research article to achieve their persuasive purposes. We also discuss differences in how writers in different disciplines favour diverse accompanying head nouns to foreground the particular aspect of information their readers are likely to find most familiar and persuasive. We conclude that existential there is a key feature in the academic author's rhetorical toolbox, allowing them to build interaction with readers and claim credit for their ideas.
\end{abstract}

\section{Introduction}

Academic writers employ a range of linguistic and rhetorical items to persuade readers of their contributions, an array which includes discoursal features such as stance (Hyland, 2005b; Jiang \& Hyland, 2015) and metadiscourse (Hyland, 2005; Mur-Dueñas, 2011), and syntactic patterns, such as anticipatory it (Hewings \& Hewings, 2002), evaluative that (Auhtor $2 \&$ 
Other, 2005), and passives (Seoane, 2013). One feature which has received relatively little attention, however, is existential there (as in "there are significant differences"). This is a structure with a 'secret life', long discussed by grammarians and linguists, much proscribed by style guides, but commonly used by academic writers. This secret life refers to how the functions of the structure suggested by linguists help shape academic persuasion. This lack of attention creates difficulties for L2 writers (e.g. Hinkel, 2004; Palacios-Martínez \& MartínezInsua, 2006), especially as patterns with existential there are typically taught with locally physical referents ("there is a cup on the table") and with no attention to rhetorical functions.

Existential there, however, is frequent in texts (Huckin \& Pesante,1988; Huckin, 1993), and attracted some interest in terms of functions (e.g. Breivik, 1999; Martínez Insua, 2004) and verb choices (Hiltunen, 2010), yet little is known about how it works in academic writing. Which nouns typically accompany the structure in academic texts? How are they are used to achieve specific communicative purposes across different stages of research articles? Do they vary across disciplines? Here we address these questions by examining the frequency, form and functions of existential there in a corpus of 80 research articles from four disciplines. The results help to illuminate the functional behaviour of the structure and contribute to our understanding of academic argument more generally. Before discussing our study, we begin by describing the functional characteristics of existential there identified in the literature.

\section{Functions of Existential there}

Existential there affirms the existence or presence of something (or its non-existence or nonpresence). It is used with an intransitive verb, typically a copular or linking one, most often in there be + indefinite noun group (modification/adverbial expansion) structures such as the following ${ }^{1}$ : 
(2) There is a reality to the equivalence of things which is expressed through the form of value.

[Sociology]

(3) there were eight to 12 replicate plants within each treatment (control and soil moisture deficit) randomly located in the controlled environment chamber.

[Biology]

In these examples, the indefinite noun group is referred to as the notional subject (Biber et al., 1999; Quirk et al., 1985) in order to be distinguished from there itself, which is the grammatical subject and pushes the clausal subjects towards the end of the sentence.

In addition to this main function, Huckin and Pesante (1988), and Carter-Thomas and Rowley-Jolivet (2001) recognize two additional functions, derived from this basic one (see Martínez Insua, 2004 for a wider discussion of functions). In general, the literature proposes three main functions of existential there:

- To assert the (non)existence of entities

- To mark enumeration

- To summarise given information

\subsection{Function one: To assert the (non)existence of entities}

Existential there, as we have noted, essentially asserts or denies the existence of something and often this is to show an association between two assertions. We can see this clearly in (4) where the author comments on the ineffectiveness of a previously reviewed explanation and then announces the presence of a theoretical motivation for this interpretation.

\footnotetext{
${ }^{1}$ All examples are taken from our corpus of academic research articles described in section 3. Existential there is underlined, the indefinite noun group is italicised and disciplinary source of each example is noted in square brackets.
} 
(4) We just want to point out that this explanation does not address the description of the formal properties of interlanguage. There has to be an underlying grammar that allows for this interpretation, even if it is so complicated to the point where L2 speakers cannot use it due to processing limitations.

[Applied linguistics]

From a pragmatic point of view, Lambrecht (1994, p.177) argues that we can interpret this function as:

that of presenting or introducing a referent into the 'place' or 'scene' of the discourse and thereby of raising it into the addressee's consciousness, rather than of asserting its mere existence.

In other words, existential there allows "the addressee to prepare for something that is about to be introduced" (Halliday and Matthiessen, 2014, p. 308). By filling the theme position with minimal information, the 'empty' subject there helps to introduce the new message and guide readers to a preferred interpretation. So there in (4), for example, points to the upcoming new information conveyed by the noun group an underlying grammar..., which carries the focus of the message, so bringing the new element to readers' awareness (Breivik, 1999; CelceMurcia \& Larsen-Freeman, 1999; Downing, 2015).

Similarly, Thompson (2014) argued that "existential there functions as a 'pass' option", pointing forward to "the topic of the clause, and, in many cases, of the following stretch of text" (p. 166). In (5) below, existential there sends a "presentative signal" (Breivik, 1999, p.12) to the proposition about synchronization and directs readers' attention to the new information, thus giving it special prominence (Kolln \& Gray, 2010).

(5) In order for the interaction to generate this experience, it has to exhibit certain qualities. First, there must be a synchronization of interpersonal moves into various interaction ritual chains. When this occurs, interactions are smooth and predictable, and persons feel they understand one another.

[Sociology] 
We also see here that use of the structure adheres to the end-weight principle of putting short, simple there first and long, complex constituents last, thus promoting readability (Biber et al., 1999). This not only allows academic authors to condense more information into the noun group, which carries the central focus of the message (a synchronization of interpersonal moves into various interaction ritual chains), but also to pick this up as the theme of the following sentence (when this occurs). This thematic progression assists the flow of information through the text and guides readers in developing a coherent interpretation of the message. This leads us to a second function of existential there.

\subsection{Function two: to mark enumeration}

A second function is to enumerate (Huckin \& Pesante, 1988; Celce-Murcia \& LarsenFreeman, 1999; Carter-Thomas \& Rowley-Jolivet, 2001). Biber et al. (1999, p. 952), for instance, take this as "a springboard in developing the text when it is used to introduce a series of elements". This signalling role is also referred to as a prospective function (Martínez-Insua, 2004), and we can see this prospective signalling of upcoming information clearly in the following examples. In (6), there are several strategies sets up a prediction committing the writer to enumerate (Tadros, 1985, p. 14). Here existential there introduces a series of strategies, focusing particularly on a sequence of methods rather than on a single item. This enumeration helps to organise cohesive discourse and create a coherent message as it prepares readers to anticipate what follows in the subsequent sentences and helps them better understand the upcoming elements (early methods, a more recent development and Foll \& Gappiotti's model).

(6) There are several strategies to detect such outliers, depending on summary statistics and test assumptions. Early methods were based on... A more recent development implemented a Bayesian method... Finally, under a model selection framework... Foll \& Gaggiotti (2008) developed a Bayesian method...

[Biology]

The enumeration function is clearer in (7) where the predicted elements (MOGUI and the Interface Hypothesis) span more than ten paragraphs. The opening, there are two well-known 
approaches sends a predictive cue to readers about the unfolding of the texts and facilitates readers' reception of the chunks of information.

(7) There are two well-known approaches to optionality in the L2 literature that are worth mentioning in order to situate the MG proposal:

\section{MOGUL}

(Paragraph 1)

$\cdots$

(Paragraph 10)

The Interface Hypothesis

(Paragraph 1)

(Paragraph 6)

[Applied linguistics]

Without such a predictive signal, readers may find it difficult to follow the extended argument.

\subsection{Function three: to summarise given information}

Although the basic function of existential there is to state the existence or non-existence of something, the information expressed in the notional subject is not always completely new to readers. Instead it may be used to summarise or reiterate points made earlier in the discourse (Carter-Thomas \& Rowley-Jolivet, 2001; Hiltunen, 2010; Martínez-Insua, 2004). In Example (8), the author seeks to reject the biological hypothesis about $M C M-3$ proteins and present the idea that the licensing reaction is essentially unidirectional, by summarising what has been found in the experiments.

(8) However, ORC and CDC-6 were released from chromatin when chromosomes decondensed at the start of interphase, which likely marks the end of the licensing period. FRAP experiments showed that MCM-3 accumulated steadily on chromatin during anaphase, and this rate of accumulation was essentially unchanged after photobleaching. This suggests that there is no significant unloading of MCM-3 proteins during this period and that the licensing reaction is essentially unidirectional.

[Biology] 
In summary, these three functions contribute in powerful ways to the organisation of a message. Underlying each of them, however, is textual interaction in which authors employ this rhetorical device to guide readers through an argument and steer them to the author's perspective. Compared with other grammatical patterns such as passives and evaluative that, existential there also has the advantage of bringing new information into readers' attention and ensuring a smooth information flow between clauses (Carter-Thomas \& Rowley-Jolivet, 2001). This has given the structure an important role in scientific writing since the beginning of the nineteenth century (Banks, 2008) while passives (Seoane, 2013) and evaluative that (Hyland \& Jiang, 2018) have both declined in frequency. Thus it is a coherent structure with a function made effective by the interactivity of academic persuasion. It not only contributes to the reader-friendliness of a text but exhibits "the writer's assessment of the reader's assumed comprehension capacities, understandings of related texts, and need for interpretive guidance" (Hyland, 2005, p.50).

However, style guides and textbooks tend to warn academic writers to stay well away from existential there. Huckin \& Pesante (1988), for example, found a wide range of writing handbooks set against using the structure. They quote The Prentice-Hall Handbook for Writers (Leggett, Mead \& Charvat, 1978) which warns students to "keep your sentences awake by not putting them into those favorite stretchers of the passivists, There is.., It is..., and the like" (p.50) and The Practical Stylist (Baker, 1979) which tells us to "be suspicious of sentences beginning with there are, there is, it is" (p.311). These prescriptions continue in more recent texts, such as Belmont and Sharkey (2011) and Hall, Birkerts (2007) and Lannon (2006). There, behaving like a grammatical subject to position the actual subject further into the sentence, has often been seen as "non-referential, dummy and empty" (Celce-Murcia \& Larsen-Freeman, 1999, p. 444) because it merely "fills space in a sentence without contributing to its meaning" (Hall \& Birkerts, 2007, p. 339). Thus writers are typically advised to avoid it in professional writing. 
This disparity between the functions suggested by linguists and the prescriptions given by style guides encouraged us to explore authorial practices empirically. To be specific, we ask the following questions:

(1) What are the frequencies, forms and functions of existential there in academic prose?

(2) How is this structure used in different sections of articles?

(3) To what extent does its use vary across disciplines?

\section{Corpus and analysis}

We compiled a corpus from 80 research articles published between 2014 and 2015 in the leading journals in four disciplines, totalling 0.85 million words. Papers were selected to represent disciplines in the soft knowledge fields (applied linguistics and sociology) and the hard sciences (electronic engineering and biology). Four papers were taken at random from each of five journals in each discipline which had achieved the top ranking in their field according to the 5-year impact factor published by Thomson Reuters's Web of Knowledge ISI in 2015 (Appendix 1). Their representativeness was also confirmed by consulting researchers in each discipline.

Only empirical research articles were included to ensure a rough comparability of papers across disciplines, and we categorised the rhetorical sections by Introduction, Methods, Results and Discussion (IMRD), following the typical structure of empirical research articles (Swales, 1990). We understood Results as a section which focused on reporting and commenting on specific findings and Discussion those that concentrated on highlighting and evaluating the findings. We included data from the Conclusion or Summary section of texts in Discussion too. Many texts were found to have a literature review, so this was also added. 
We searched the corpus for there using AntConc (Anthony, 2014), a freeware concordancing and text analysis programme, and then manually examined every instance to eliminate all cases (only 9) of the locative adverb there (as in "As can be seen there in text one..."). To explore the options of head nouns of notional subjects (i.e. the word carrying the main meaning in a noun phrase) and their rhetorical role in the construction of disciplinary knowledge, we coded all nouns following existential there using the categorisation proposed by Jiang \& Hyland (2016). Strictly, while the classification concerns types of unspecific abstract nouns, the categories offered us a useful way to code the content writers referred to through different choices of nouns. For example, plant and paper are used to represent objects, while difference and gap construct relations between entities. A complete categorisation together with our modifications is given in Section 6. We also considered whether the existential there structures we observed were in a basic form ("there is a silence") or whether more information was packaged using modification and adverbial expansion ("there are widespread new principles of text-making composition").

In addition, verb forms were also considered, whether copular be or other verbs such as exist, and we also coded copular be, whether in a simple form or other forms such as appear to be and may be, since they formulate new information in different ways (Biber et al., 1999).

When coding the functions of existential there, we read each concordance example and decided what its main purpose seemed to be in context. We then assigned it to a discrete category, depending on whether it was asserting, enumerating or summarising information. All the coding was done using MAXQDAplus (2012), a qualitative data analysis tool and a full coding scheme is provided in Appendix 2. To increase reliability, each author independently coded the concordanced examples (1) to determine the function of each use of existential there and (2) to classify the nouns following existential there using our categories (see Section 6). We achieved $97 \%$ and $96 \%$ agreement in these two steps. Then the results were 
normalised to 10,000 words to allow comparison across the corpora, and log likelihood tests conducted to determine statistical significances.

\section{Overall results}

We identified 697 cases of existential there in the corpus, averaging 8.7 cases per article and 10.7 cases per 10,000 words. This figure is higher than Huckin and Pesante (1988) found in popular magazines such as Time but lower than in reference books such as Encyclopaedia Britannica. This difference reflects both the type of information presented and the writer's assessment of readers' processing needs. Reference books normally carry a great deal of codified knowledge in a small space which makes it hard reading (Huckin \& Pesante, 1988). The compilers therefore seek to make content accessible through more textual support. This rhetorical context contrasts with magazines which typically have more space to develop a narrative of news and stories, making the need for reading support less urgent.

Academic research articles sit between these two genres. The information and claims they contain may not appear as convoluted to a disciplinary scholar as Encyclopaedia Britannica does to a general reader, but academic writers still employ interactive resources to make their texts organised, coherent and persuasive. Existential there is a common rhetorical option to achieve this, helping writers to naturally introduce a new topic. In the examples below, we see writers evaluating the instruction approach in (9), and within a concessive structure establishing a coherent transition between negative and positive features of using corpora before building further arguments in (10).

(9) Approaches to instruction which make meaning primary, such as taskbased instruction, ... But there are pitfalls with such an approach, generally stemming from the consequences for form of putting such an emphasis on meaning.

[Applied linguistics]

(10) Although there are drawbacks, there are at least three main advantages of using corpora in comparison with direct observations.

[Applied linguistics] 
It is also important to note in the above examples that the notional subjects, pitfall, drawback and advantage, project judgments about something, indicating that the 'empty' subject of there offers a powerful mechanism for the expression of authorial stance. This is because existential there "relieves the writer of any responsibility for the viewpoint", presenting pitfall, drawback and advantage as "a given existential statement" (Davies, 1988, p. 197). In addition, in the case of there are at least three main advantages in (10), advantage constructs a frame for readers' understanding of the upcoming discussion, guiding their view to the author's positive evaluation of using corpora.

In terms of the rhetorical functions, Figure 1 shows that this structure is most frequently used in our corpus to assert the (non)existence of entities, amounting to 537 instances or $77 \%$ of all cases, and another $18 \%$ is used to summarise given information. As we might expect, the construction mainly affirms the existence of something, with roughly $70.5 \%$ of cases, and Figure 2 presents the proportion of existence and non-existence affirmed by the existential there construction. In academic prose, however, it is normal to either problematize previous studies (11) or refute a scientific hypothesis (12), and it is this which means negative assertions form a higher proportion of academic registers than the $10 \%$ reported by Halliday (2005) for general English. As seen in the extracts below, existential there offers academic authors a handy rhetorical device to affirm the non-existence of research subjects and achieve this particular communicative purpose in academic contexts.

Figure 1 Frequency of the rhetorical functions of existential there construction
Figure 2 Frequency of affirming (non)existence by existential there construction 

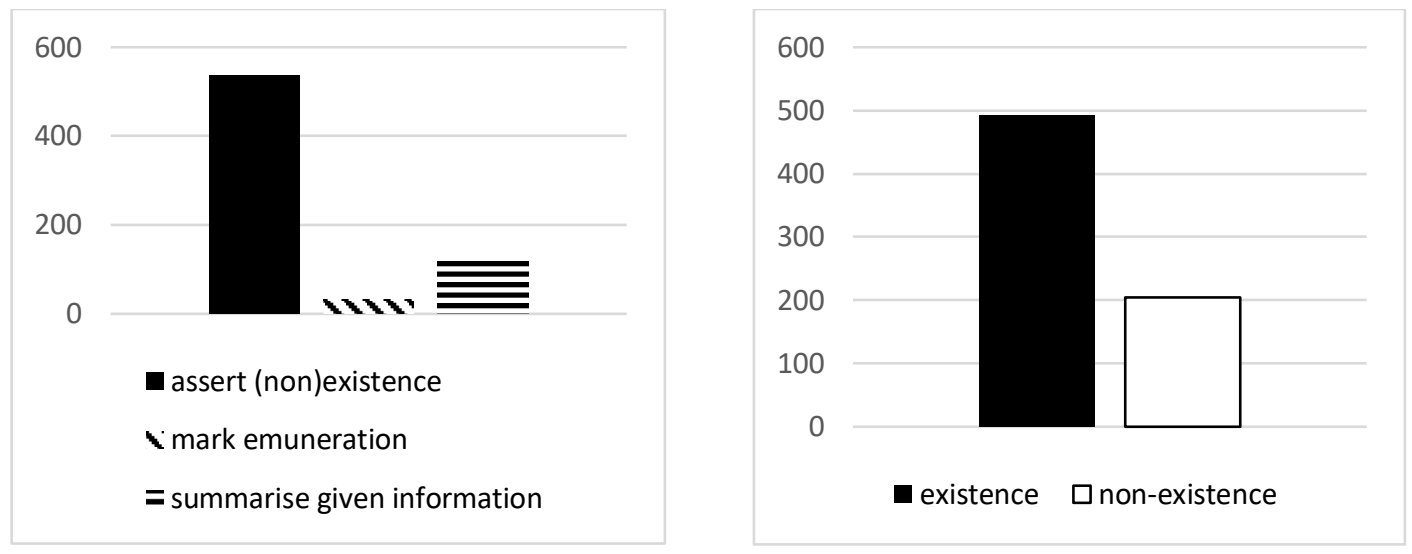

(11) Although there is no universal agreement about the degree to which EAL researchers in general struggle to get published in English (Canagarajah, 1996; Flowerdew, 1999a; Wood, 2001), EAP practitioners who work to support novice researchers from EAL backgrounds are clear that the difficulties for them are considerable.

[Applied Linguistics]

(12) There was no significant variance between villages with samples from both forest age classes pooled.

[Biology]

Overall, the head nouns forming notional subjects are more often in singular than plural forms (416 vs 281 cases) with differences being the most frequent, amounting to $3.9 \%$ of all cases. This may show writers' reliance on existential there to prepare readers for the presentation of differences which might extend over several sentences or paragraphs. This interactive preparation both assists readers to navigate several intertwined propositions and enables writers to accomplish their communicative ends more effectively. For example, in (13) there are significant differences not only introduces a new topic about algorithms but also predicts the connection between Figure 5 and Figure 6. Similarly, the applied linguist in (14) set an interpretive frame on the relationship between the account of acknowledgements and jokes, labelling it as differences, in order to make the connection more accessible.

(13) there are significant differences between the two algorithms with the $\mathrm{p}$ value very close to 0 . Figure 5 shows the mean plots and LSD intervals at 95\% confidence level ... Figure 6 shows the means obtained in the different problem sizes.

[Electronic engineering] 
(14) There are also differences regarding the types of Bathroom Formulas that receive these kinds of responses. Acknowledgements typically occur after the 'milder', neutral or euphemistic types ..., while jokes instead follow potentially more face-threatening dysphemisms ... [Applied linguistics]

In addition, among the nouns following there + be are unspecific abstract nouns, such as evidence, conclusion and choice, which are called "shell nouns" by Schmid (2000), “signalling nouns" by Flowerdew and Forest (2015), and "metadiscursive nouns" by Jiang \& Hyland (2016). These comprise $97 \%$ of the total number of nouns in the corpus under analysis. Therefore, existential there is an important lexico-grammatical structure of these nouns, but neither Schmid nor Flowerdew and Forest discuss their rhetorical use in this patterns (see Jiang, 2017 for a full review). In terms of the verb form after there, be is the most frequent, making up $93 \%$ of all cases, and may be, appear to be, and must be are the three other common forms of copular be. Other than these, exist and arise are the only verbs found in the corpus (only four instances).

While not a central part of this study, it is also worth mentioning that existential there is more frequent in soft knowledge fields than in the hard domains ( $\log$ Likelihood $=48.62, p<0.001)$ as the less assured, more explicitly interpretive foundations of knowledge in soft disciplines mean claims require more discursive support (Hyland, 2004, 2005). Table 1 summarises the frequency of existential there across disciplines. Applied linguists stands out here as making the most use of this structure ( $\log$ Likelihood $=81.09, p<0.001$ ), possibly because of writers' greater awareness of the rhetorical impact of language choices in this discipline.

Table 1 Frequency of existential there across disciplines (raw number \& per 10,000 words)

\begin{tabular}{c|cc|cc|cc|cc}
\hline & \multicolumn{2}{|c|}{$\begin{array}{c}\text { Electronic } \\
\text { engineering }\end{array}$} & \multicolumn{2}{|c|}{ Biology } & Sociology & \multicolumn{2}{|c}{$\begin{array}{c}\text { Applied } \\
\text { linguistics }\end{array}$} \\
\hline Total & 77 & 6.4 & 120 & 6.9 & 194 & 8.4 & 306 & 12.3 \\
\hline
\end{tabular}


This example illustrates something of this rhetorical sensitivity of applied linguists.

(15) There are clear reasons for the adoption of task-based approaches, principally associated with their potential engagement of acquisitional processes, there is underlying psycholinguists research which, to some extent is supportive, and there is a range of specifically task-based second language research which is helpful in evaluating this type of instruction. On the other hand, there are arguments, both linguistic and psychological, for why a focus on meaning may not engage such acquisitional processes, there is psycholinguistic evidence which argues for a clear role for explicitness and consciousness, for the manipulation of attentional focus, and for the existence of dual modes of processing, structural and exemplar-based. This discrepancy places proponents of task-based instruction in a difficult position, since, while it is clear that there are advantages to using such an approach, it is difficult to know how strongly to argue this position... [Applied linguistics]

There are only seven clauses in three sentences in this example, but the extract contains as many as six existential there structures. While this is perhaps an extreme case, it reflects the writer's awareness of textual artifice and manipulation in negotiating knowledge claims.

In sum, academic writers in these four fields generally ignore the style guides and make frequent use of existential there in their texts, whether to assert the (non)existence of material, recapitulate information, enumerate or otherwise organise the discourse. What we show here is that these functions vary greatly across research article sections, that authors in different disciplines chose and expand the head nouns in different ways, and that these functional choices vary across disciplines.

\section{Variations across sections}

The distribution of functions of existential there across sections is summarised in Table 2. It shows that the literature review carries the most frequent occurrences, averaging 15.7 cases 
per 10,000 words (log Likelihood $=38.91, p<0.001)$. This reflects the rhetorical nature of what Swales (1990), for example, sees as one of the most evaluative sections of the research article.

Table 2 Distribution of existential there across research article sections (per 10,000 words)

\begin{tabular}{|c|c|c|c|c|c|c|}
\hline & Introduction & Review & Methods & Results & Discussion & Total \\
\hline Total & 8.9 & 15.7 & 5.4 & 12.4 & 8.4 & 10.7 \\
\hline \multicolumn{7}{|l|}{ Functions } \\
\hline assert (non)existence & 7.6 & 11.0 & 4.0 & 6.8 & 6.5 & 7.3 \\
\hline $\begin{array}{l}\text { summarise given } \\
\text { information }\end{array}$ & 1.1 & 3.8 & 1.0 & 5.1 & 1.2 & 2.9 \\
\hline enumeration & 0.2 & 0.9 & 0.4 & 0.5 & 0.7 & 0.5 \\
\hline
\end{tabular}

As Bruce (2014) and Kwan et al. (2012) have shown, the review section is more interactively complex than other sections since it critically engages with particular texts, authors and the disciplinary community. To build authorial novelty, a writer must first establish consensual knowledge and the following extracts show how existential there gives writers a compelling way to present the existing literature (16) or point out the insufficiency of previous studies (17). In this section existential there often occurs in sequences, intensifying the persuasive effects of acknowledging the literature or problematizing its deficiency.

(16) There is a vast amount of literature on the design and analysis of manufacturing systems let alone material handling systems by themselves. With few exceptions, there has been some literature devoted to the total integration of_these two areas from an analytical point of view, however there has been more effort from a simulation modeling perspective.

[Electronic engineering]

(17) There may be a lack of interest on the part of the learner either in the goal of becoming more native-like or simply in making the effort to change and re-organize an interlanguage system. There may also be impoverished input (or instruction), such that necessary conditions for restructuring are 
impaired. But there might also be problems even if the above two influences are not present.

[Applied linguistics]

Turning to the different functions, we can confirm that existential there is used most often to announce the presence or absence of something, particularly in review and introduction sections. As the following examples (18) and (19) indicate, authors essentially refer to the literature through this structure in the literature review. Example (18) also illustrates that this structure allows academic writers to incorporate citations as generalisation in articles where material is ascribed to two or more authors (Hyland, 1999), a citation pattern which is gaining prominence in academic writing (Hyland \& Jiang, 2017).

(18) There have been many studies characterizing the alpha diversity of ectomycorrhizal communities in recent years (Horton \& Bruns 2001; Dighton et al. 2005).

[Biology]

(19) There is an almost total neglect in the literature using VRM of research participants' 'symbolic and communicative' competencies in that culture. There are remarkably few discussions of how people taking part in VRM projects may bring a range of visual knowledges and skills to bear on what they are asked to do.

[Sociology]

The introduction section, on the other hand, is typically concerned with presenting new topics of key interest in the field (20) and (21), thereby claiming centrality at the outset where "members are asked to accept that the research about to be reported is part of a lively, significant or well-established research area" (Swales, 1990, p.144).

(20) there is growing interest in the use of specialised and personal corpora.

[Applied linguistics]

(21) there is a politics within Marx's account of the commodity.

[Sociology]

Most examples of existential there in results sections are used to summarise what the authors have found in their research, especially when making a generalization concerning knowledge claims (22) and (23). 
(22) Table 13 shows the total cell imbalance ( $\mathrm{Z}$ 2) and the total cost values (Z 1) for each non-dominated solution. The comparison between the first objective $\mathrm{Z} 1$ and the workload imbalances of cells in the second objective $\mathrm{Z}$ 2 reveals that there is $a$ reverse relationship between objectives $\mathrm{Z} 1$ and $\mathrm{Z} 2$.

[Electronic engineering]

(23) In contrast to AmE, nearly half the BNC instances did not contain any (semi-) modals, but instead only main verbs. Thus, it appears that there is $a$ dialectal difference between $\mathrm{AmE}$ and $\mathrm{BrE}$...

[Applied linguistics]

The enumeration function is more frequent in Discussion and Review than other sections. Analysis of the identified instances shows that writers typically use existential there to enumerate and take account of the practical applications of the model proposed (24) or spell out the theoretical implications suggested by the writer's research (25).

(24) There are many high-power heating applications for the SRR, in the first instance within the field of microwave-assisted chemistry...

[Electronic engineering] (25) There were some instances which required careful attention. Firstly, the specific needs of all the target students ... Secondly, the research needed careful planning and execution... [Applied linguistics]

When we look more closely at the information the structure points to, we find preferences for prospective and retrospective reference (Martínez-Insua, 2004) also vary greatly across different sections of the article (Table 3).

Table 3 Distribution of uses of existential there across sections (per 10,000 words \& ratio) 


\begin{tabular}{rccccc}
\hline Prospective & 7.8 & 11.9 & 4.4 & 7.3 & 7.2 \\
Retrospective & 1.1 & 3.8 & 1.0 & 5.1 & 1.2 \\
Ratio Retro:Pros & $\mathbf{1 4 . 1}$ & $\mathbf{3 1 . 9}$ & $\mathbf{2 2 . 7}$ & $\mathbf{6 9 . 9}$ & $\mathbf{1 6 . 7}$ \\
\hline
\end{tabular}

Existential there works prospectively to introduce something new in the subsequent discourse and retrospectively to point back to reiterate, summarise or reinterpret the preceding message (Martínez-Insua, 2004). Although prospective use is generally more frequent in academic texts compared to many other registers, we find retrospective existential there to be proportionately higher in results and review sections. As shown in (26) and (27), the authors may perceive a greater need in these sections to encapsulate previously mentioned findings or reinterpret previous studies to claim for the significance and relevance of their research.

(26) The values in the third and fifth column are remarkably consistent across all values of the squared coefficient of variation $\mathrm{s}^{2}$ of the $M / G / 1 / K$ queue. This demonstrates that there is a certain robustness or insensitivity of the $M / G / c / c$ queue to its input distribution. [Electronic engineering]

(27) These types of experiences provide empirical support for poststructural leisure theory, which avoids dualistic categories (e.g. work/leisure, public/private) and eschews universalistic understandings of leisure meant to hold true across time and space (Aitchison, 2003). Poststructural scholars see leisure instead as contextual, flexible and fragmentary (Aitchison, 2003; Rojek, 1995; Wearing, 1998). Following the earlier discussion, we have seen that there are advantages with this approach.

[Sociology]

As seen above, existential there helps anticipate readers' processing needs at critical points and encapsulates what has been discussed, but this also helps guide readers towards preferred conclusions.

\section{Variations in noun choices}


As mentioned, the choice of head noun is an important pragmatic tactic when writers use existential there to build persuasive academic arguments. To determine what the writers convey through the nouns they use to accompany existential there, we drew on the categorisation proposed by Jiang \& Hyland (2016), shown in Table 4. This shows that nouns express how academic writers mark entities, describe attributes of entities and discuss the relations between entities.

Table 4 An expressive classification of nouns in academic texts (Jiang \& Hyland, 2016)

\begin{tabular}{|c|c|c|}
\hline Entity & description & examples \\
\hline object & textual and physical objects & article, study, gene, operator \\
\hline evidentials & events, processes, and evidential cases & change, case, observation \\
\hline discourse & verbal propositions and speech acts & argument, claim, conclusion \\
\hline cognition & cognitive beliefs and attitudes & decision, idea, notion, aim \\
\hline species & types and kinds of entities & type, kind, category, something \\
\hline Attribute & description & examples \\
\hline quality & $\begin{array}{l}\text { traits that are admired or criticised, valued } \\
\text { or depreciated }\end{array}$ & advantage, difficulty, failure \\
\hline manner & circumstances of actions \& states of affairs & time, method, way, silence \\
\hline status & epistemic, deontic and dynamic modality & possibility, trend, choice, ability \\
\hline Relation & description & examples \\
\hline $\begin{array}{r}\text { cause-effect, } \\
\text { difference, etc. }\end{array}$ & cause-effect, difference, relevance & reason, result, difference \\
\hline
\end{tabular}

According to this classification, nouns which define entities do so by either conveying writers' judgement of objects, events, discourses or cognition. When labelling objects nouns typically refer to a concrete piece of research, such as report, paper and study. But in the $10 \%$ sample of this current study, we also found nouns marking physical objects, such as gene and operator, so we included these cases in this category. Evidential nouns refer to either actions and processes or events, with examples such as change, case, observation and finding being frequent. We also found process-related technical nouns such as synchronization and pause in this study and so included them in this category. Discourse nouns describe verbal 
propositions and speech acts, such as argument, claim and conclusion while Cognition nouns concern beliefs, attitudes and elements of mental reasoning, such as decision, idea, notion and aim. Additionally, in this study we identified some nouns which referred to types of entities, such as type, kind and something, so a new subgroup Species is added in this category.

Nouns referring to attributes concern evaluations of the quality, status and formation of entities. Thus nouns pertaining to quality assess whether something is admired or criticised, valued or disparaged. Here assessments occur on a plus or minus scale (e.g. good-bad, important-unimportant), typically involving nouns such as advantage, difficulty and failure. Nouns relating to manner, in contrast, describe the circumstances and formation of actions and states of affairs. Nouns such as time, method and way depict either a connection to place and time, the way in which actions are carried out or the frequency with which events occur. Nouns which concern status express judgments of epistemic, deontic and dynamic modality. Epistemic modality concerns degrees of possibility such as likelihood and truth; deontic modality bears on obligation and necessity such as need and obligation; dynamic modality describes ability, opportunity and tendency such as ability, potential and tendency.

Finally, nouns encode how a writer understands the connections between items of information in a proposition, conveying relations such as reason, result and difference. Thus the categories reveal what content academic writers are most concerned with, and in order to explore the information they seek to foreground in using existential there, we examined each instance to assign head nouns in notional subjects to these semantic categories.

\subsection{Distribution across rhetorical sections in research articles}

To align with genre expectations and maximize their persuasive options in different moves, writers vary their use of existential there and select different head nouns. Table 5 shows the distribution of different noun categories across research article sections.

Table 5 Distribution of the noun categories across research article sections (per 10,000 words) 


\begin{tabular}{rcccccc}
\hline & Introduction & Review & Methods & Results & Discussion & Total \\
\hline Entity & $\mathbf{6 . 0}$ & $\mathbf{9 . 8}$ & $\mathbf{3 . 2}$ & $\mathbf{6 . 1}$ & $\mathbf{4 . 8}$ & $\mathbf{7 . 8}$ \\
object & 1.5 & 3.3 & 1.3 & 1.6 & 1.0 & 2.3 \\
evidentials & 2.0 & 3.0 & 1.0 & 2.9 & 2.0 & 2.5 \\
discourse & 1.1 & 1.1 & 0.4 & 0.8 & 0.9 & 1.6 \\
cognition & 1.1 & 1.9 & 0.4 & 0.5 & 0.5 & 1.1 \\
species & 0.3 & 0.5 & 0.1 & 0.3 & 0.4 & 0.3 \\
\hline Attribute & $\mathbf{1 . 6}$ & $\mathbf{3 . 9}$ & $\mathbf{1 . 3}$ & $\mathbf{2 . 2}$ & $\mathbf{2 . 4}$ & $\mathbf{1 . 6}$ \\
quality & 0.4 & 1.6 & 0.3 & 0.8 & 0.3 & 0.4 \\
manner & 0.5 & 1.1 & 0.7 & 0.6 & 1.2 & 0.5 \\
status & 0.7 & 1.2 & 0.3 & 0.8 & 0.9 & 0.7 \\
\hline Relation & $\mathbf{1 . 3}$ & $\mathbf{2 . 0}$ & $\mathbf{0 . 9}$ & $\mathbf{4 . 1}$ & $\mathbf{1 . 2}$ & $\mathbf{1 . 3}$ \\
\hline
\end{tabular}

The most common noun choices involve reference to entities, with evidential nouns, concerning events, processes and evidential cases, the most frequent sub-category, comprising $23.4 \%$ of all the nouns accompanying there $+b e$. Evidential nouns appear most frequently in results and review sections $(\log$ Likelihood $=35.26, p<0.001 ; \log$ Likelihood $=24.55, p<$ 0.001). Here writers either argue for the existence of evidence from previous studies in connection with the research gap they are advancing (28) and (29), or foreground the evidential results from their own research in support of the knowledge claim they are making in the results section (30) and (31).

(28) There is accumulating evidence (see review in Carr and Curren 1994) that explicit learning of structured material is generally superior to implicit learning.

[Applied linguistics, Review]

(29) Although the error compensation proposed by Park and Kim decreases the average relative error, there are many individual cases where the relative error is increased.

[Electronic engineering, Review]

(30) there was evidence for a reduced relative sensitivity to $\mathrm{CO} 2$ compared to wildtype between 100 120 Pa CO2 (Fig. 9b).

[Biology, Results]

(31) There is evidence to support this possibility in the recommendations stages of the larger corpus.

[Applied linguistics, Results] 
Thus when writers bring in evidence to support a proposition, existential there allows them to foreground the evidential nouns and the clause specifying it to highlight the relationship between the two clauses as claim and supporting evidence.

Review and results sections also contain a larger number of object nouns than other sections. The concordance lines show that in review sections writers attach more importance to textual objects to stress the existence of previous studies (32), while in results sections they give more emphasis to the physical objects they have found (33).

(32) there is still a dearth of theoretically informed studies that investigate, systematically and longitudinally, the role of students' goals for writing from cognitive, motivational, and self-regulatory perspectives ...

[Applied linguistics, Review]

(33) there were many more downregulated genes with ABRE core motifs in their promoters (Table 4).

[Biology, Results]

Within entities, both discourse and cognition nouns are used more frequently in introduction and review sections of articles. As we can see in the following examples, by using existential there to introduce a proposition and goal, writers set out their stall, promoting their own aim or novelty claim at the outset (34), or lay the foundation for it (35).

(34) There is a much stronger emphasis here on parents' delegated responsibilities for children's welfare. [Sociology, Introduction]

(35) There are, however, few descriptions in the literature as to what the texts these students write should look like, nor any cross-university studies which have examined these texts in detail. [Applied linguistics, Review]

Also worth mentioning from the figures in Table 5 is that discussion section sees a relatively frequent use of nouns evaluating attributes and results section contains high frequencies of relation nouns to discuss the connections between entities. As we have mentioned above, in discussions writers typically spell out theoretical implications and practical applications, but 
in terms of the nouns used, they often encode their judgement of the status and manner of how research subjects may develop (36) or how future research should proceed (37).

(36) For large cargo, there is a high likelihood that larger than wild-type genomes will recombine to smaller sizes. [Biology, Discussion]

(37) there are also various new directions in which researchers could proceed. ...

[Sociology, Discussion]

When talking of the results, writers are most likely to place their findings immediately following the existential there structure (38) and (39), giving them prominence because the unexpected (non)existence of variation or difference may most intrigue readers and generate interest in the study.

(38) In fact, there is little variation in the WIP in the conveyors across s 2 values. This is an interesting result. [Electronic engineering, Results]

(39) there was a significant difference in the acquisition of relative clauses in English between L1 Spanish and L1 Japanese speakers...

[Applied linguistics, Results]

\subsection{Differences across disciplinary fields}

Firstly, it is interesting to note that a number of highly frequent nouns occur far more often in existential there constructions than other structures such as "noun + post-nominal clause" and “determiner + noun" (Jiang, 2017). The top ten are difference, reason, link, correlation, effect, tendency, relation, relationship, variation and disagreement. Almost all of these are relation nouns, indicating that academic authors are inclined to use existential there to construct the connection between propositional information. Furthermore, the functions of nouns in existential there structures also vary across disciplines (Table 7).

Table 7 Distribution of the noun categories across the disciplines (per 10,000 words) 


\begin{tabular}{|c|c|c|c|c|}
\hline & $\begin{array}{c}\text { Electronic } \\
\text { engineering }\end{array}$ & Biology & Sociology & $\begin{array}{c}\text { Applied } \\
\text { linguistics }\end{array}$ \\
\hline Entity & 3.8 & 4.2 & 5.1 & 5.8 \\
\hline object & 1.3 & 1.2 & 1.1 & 1.3 \\
\hline evidentials & 1.6 & 2.1 & 1.8 & 2.3 \\
\hline discourse & 0.1 & 0.6 & 0.9 & 0.8 \\
\hline cognition & 0.5 & 0.2 & 1.0 & 1.0 \\
\hline species & 0.3 & 0.1 & 0.3 & 0.4 \\
\hline Attribute & 1.6 & 1.1 & 1.5 & 3.4 \\
\hline quality & 0.4 & 0.4 & 0.5 & 1.0 \\
\hline manner & 0.7 & 0.2 & 0.7 & 1.2 \\
\hline status & 0.5 & 0.5 & 0.3 & 1.2 \\
\hline Relation & 1.0 & 1.7 & 1.7 & 3.2 \\
\hline Total & 6.4 & 6.9 & 8.4 & 12.3 \\
\hline
\end{tabular}

Within the entity category, we find evidential nouns used frequently in all disciplines, but discourse and cognition nouns are significantly higher in the soft science texts (log Likelihood $=17.93, p<0.005 ; \log$ Likelihood $=24.45, p<0.005)$. This reflects the more discoursal argument patterns of the soft knowledge fields which seek to engage readers in theoretical argument more than empirical demonstration, making examples such as these common:

(48) There is frequently an assumption that the visual will act as a trigger to an oral response or that the visual and the verbal will somehow strengthen one another.

[Sociology]

(49) there are a number of critiques of task-based instruction that could be made...

[Applied linguistics]

Biologists, on the other hand, rely more on relation nouns to underscore unexpected results, and promote the news value of their research through existential there. We can get a taste of this rhetorical use of language from these two typical examples:

(50) Despite their common evolutionary origin and the nuclear location of both genes, there are more similarities between animal and cytosolic FBPase than between the chloroplastic and cytosolic isozymes.

[Biology] 
(51) There was considerable heterogeneity among accessions in the response to the soil moisture deficit treatment with 4488 (of which 1016 show significant interaction in $\log 2$ transformed expression values) and 2697 (500 in $\log 2$ values) genes ...

[Biology]

This orientation to the various relations among biological components is important in biology and existential there enables writers to place findings in the focus of readers' attention.

As to nouns expressing writers' evaluation of attributes, authors in the soft fields also make greater use of these notional subjects $(\log$ Likelihood $=13.41, p<0.001)$. Once again, this supports research which indicates how authors in the humanities typically build knowledge through arguments which depend on their personal interpretations and negotiations with readers (Hyland, 2004; Jiang \& Hyland, 2016). The positions taken by these writers, for example, are clearly foregrounded by their choice of nouns:

(52) There are two types of challenges entailed in maximising the potential of personal corpora: pedagogical and technical. First, ... [Applied linguistics]

(53) there is a great deal of uncertainty on what our signals mean and how we can best forge a sense of interpersonal connection.

[Sociology]

In sum, academic writers make rhetorical use of existential there to organise discourse and build interaction with readers in response to the different communicative purposes of article sections. We have also shown that authors choose different nouns to build knowledge and package information in notional subjects in a way that disciplinary readers find familiar, relevant and persuasive.

\section{Discoursal expansion of head nouns}


Discoursal expansion of existential there is another pragmatic manoeuvre writers use to achieve disciplinary persuasion. This is achieved either through pre-modification (40), postmodification (41), or adverbials (42). Alternatively, modification and adverbials are combined in the expansion of existential there construction as in (43). However, we counted each premodification, post-modification or adverbials separately as one expansion.

(40) there have been no industrially acceptable methods.

[Electronic engineering]

(41) there are moments which signal some of the concerns on this paper.

[Sociology]

(42) In particular there may be scope for future studies which deliberately aim to collect data from classrooms ... [Applied linguistics]

(43) there was a strong curvilinear relationship between the foliar chlorophyll content and SPAD values.

[Biology]

We can see from Table 6 that authors in the hard domains tend to expand each head noun more than their peers in the soft fields, and in so doing, package more information into each existential there structure (2.1 expansions per head noun in hard disciplines vs 1.6 cases in soft fields).

Table 6 Expansion of head noun in existential there across disciplines (\% of expanded nouns) 


\begin{tabular}{|c|c|c|c|c|c|c|c|c|c|c|}
\hline \multirow[b]{2}{*}{$\begin{array}{l}\text { Discoursal } \\
\text { expansion }\end{array}$} & \multirow[b]{2}{*}{167} & \multicolumn{2}{|c|}{$\begin{array}{c}\text { Electronic } \\
\text { engineering }\end{array}$} & \multicolumn{2}{|c|}{ Biology } & \multicolumn{2}{|c|}{ Sociology } & \multicolumn{2}{|c|}{$\begin{array}{c}\text { Applied } \\
\text { linguistics }\end{array}$} & \multirow{2}{*}{$\begin{array}{c}\text { Total } \\
\mathbf{1 0 0 . 0}\end{array}$} \\
\hline & & $(100.0)$ & 235 & $(100.0)$ & 337 & $(100.0)$ & 464 & $(100.0)$ & 1203 & \\
\hline modifications & 114 & $(68.3)$ & 168 & (71.5) & 261 & (77.4) & 342 & (73.7) & 1203 & (100.0) \\
\hline post-modification & 39 & $(23.4)$ & 52 & $(22.1)$ & 107 & $(31.8)$ & 140 & $(30.2)$ & 905 & $(75.2)$ \\
\hline phrase & 9 & (5.4) & 29 & $(12.3)$ & 60 & $(17.8)$ & 72 & $(15.5)$ & 338 & $(28.1)$ \\
\hline clause & 30 & $(18.0)$ & 23 & $(9.8)$ & 47 & (13.9) & 68 & $(14.7)$ & 170 & $(14.1)$ \\
\hline pre-modification & 75 & $(44.9)$ & 116 & $(49.4)$ & 154 & $(45.7)$ & 202 & $(43.5)$ & 168 & $(14.0)$ \\
\hline adverbials & 53 & (31.7) & 67 & (28.5) & 76 & (22.6) & 122 & (26.3) & 547 & (45.5) \\
\hline logic & 32 & $(19.2)$ & 51 & (21.7) & 67 & (19.9) & 104 & $(22.4)$ & 318 & (26.4) \\
\hline time/place & 21 & (12.6) & 16 & (6.8) & 9 & (2.7) & 18 & (3.9) & 254 & (21.1) \\
\hline
\end{tabular}

Typically, the discoursal expansion in the academic texts of hard disciplines is largely formed through pre-modification and adverbials, as shown here:

(44) there were eight to 12 replicate plants within each treatment.

[Biology]

(45) there is an increase in $1 \%$ deviation in computation of by the SLR.

[Electronic engineering]

Usually, writers in the soft disciplines prefer to expand the head nouns through postmodification. A comparison between (44) and (45) from the hard domains and (46) and (47) in the soft fields shows how scientists typically expand head nouns to add precision to their descriptions, while authors in the soft fields add discoursal elaboration to ensure a more diverse readership will find their arguments coherent (Autthor 2, 2007).

(46) There is substantial debate, however, about whether or not globalization is the main cause of the decline in relative wages and employment of lower-skilled workers.

[Sociology]

(47) there was no reference to the student's research process, and barely any reference to the student's work, at all. [Applied linguistics] 


\section{Conclusion}

To return to our research questions, our study shows that academic authors make frequent use of existential there, using almost 11 cases per 10,000 words, and that it performs useful persuasive purposes across sections of the research article, with more frequent use in the soft fields than in the hard domains.

We show that existential there is not "empty" as writing handbooks suggest, but is an important rhetorical tool, allowing writers to build interaction with readers and claim credit for their ideas. Its persuasive power does not simply relate to the verb and polarity in the structure as suggested in the literature (e.g. Hiltunen, 2010), but relies to a great extent on the choice of accompanying nouns and their discoursal expansion in the argument. Writers make most use of this device in review and results sections, assisting readers towards a better understanding and more coherent reading of their message, while employing evidential and relation nouns to promote the relevance and value of their ideas. Thus existential there helps writers to meet both adequacy and acceptability conditions of persuasion (Hyland, 1998). On the one hand, it assists readers in processing the text and interpret it consistently with their epistemological understanding and genre expectations, and on the other, it enables writers to adopt a disciplinary stance towards what is presented in discourse.

Contrary to handbook advice, then, the substantial frequency of existential there gives the structure considerable legitimacy, suggesting a certain automaticity by writers based on their familiarity with disciplinary practices. Our study shows that this is actually a key pragmatic feature of academic writing and supports Kolln and Gray's claim about cases of existential there that "when they are used in the right place and for the right reason, they are not redundant, unnecessary words; they are, in fact, doing an important job" (2013: 108). Our findings thus offer evidence of how authors use this structure to support their arguments by 
stepping into their texts to inform readers how they should evaluate and understand information.

\section{References}

Anthony, L. (2014). Antconc (Version 3.4.3 w) [Computer Software]. Tokyo, Japan: Waseda University. Retrieved from http://www.antlab.sci.waseda.ac.jp/ Baker, S. (1979). The practical stylist (2nd ed.). New York: Thomas Y. Crowell.

Banks, D. (2008). The development of scientific writing: Linguistic features and historical context. London: Equinox.

Belmont, W., \& Sharkey, M. (2011). The easy writer: Formal writing for academic purposes. New South Wales: Pearson Longman.

Biber, D., Johansson, S., Leech, G., Conrad, S., \& Finegan, E. (1999). Longman grammar of written and spoken English. Harlow: Longman.

Breivik, L. E. (1999). On the rhetorical function of existential there. Nordlit, 3(2), 314.

Bruce, I. (2014). Expressing criticality in the literature review in research article introductions in applied linguistics and psychology. English for Specific Purposes, 36, 85-96.

Carter-Thomas, S., \& Rowley-Jolivet, E. (2001). Syntactic differences in oral and written scientific discourse: the role of information structure. ASp, 31-33, 1937.

Celce-Murcia, M., \& Larsen-Freeman, D. (1999). The grammar book: An ESL/EFL teacher's course (2nd ed.). Boston: Heinle \& Heinle.

Davies, F. (1988). Reading between the lines: Thematic choice as a device for presenting writer viewpoint in academic discourse. The ESPecialist, 9(1/2), 173-200.

Flowerdew, J., \& Forest, R. W. (2015). Signalling nouns in English: A corpus-based discourse approach. Cambridge: Cambridge University Press.

Hall, D., \& Birkerts, S. (2007). Writing well (9th ed.). New York: Longman.

Halliday, M. A. K. (2005). Quantitative studies and probabilities in grammar. In M. A. K. Halliday \& J. J. Webster (Eds.), Computational and Quantitative Studies (pp. 130-156). London: Continuum. 
Halliday, M. A. K., \& Matthiessen, C. M. I. M. (2014). Halliday's introduction to functional grammar (4th ed.). London: Taylor \& Francis.

Hinkel, E. (2004). Teaching academic ESL writing: Practical techiniques in vocabulary and grammar. Mahwah, NJ: Lawrence Erlbaum.

Hiltunen, T. (2010). "There are good reasons for this": Disciplinary variation in the use of existential there constructions in academic research articles. In R. Lorés-Sanz, P. Mur-Dueñas, \& E. Lafuente-Millán (Eds.), Constructing interpersonality: Multiple perspectives on written academic genres (pp. 181204). Newcastle: Cambridge Scholars Publishing.

Huckin, T. N., \& Pesante, L. H. (1988). Existential there. Written Communication, 5(3), 368-391.

Hyland, K., 1998. Persuasion and context: the pragmatics of academic metadiscourse. J. Pragmatics 30 (4), 437--455.

Hyland, K., 1999. Academic attribution: citation and the construction of disciplinary knowledge. Applied Linguistics 20 (3), 341--367.

Hyland, K., 2004. Disciplinary interactions: metadiscourse in L2 postgraduate writing. Journal of Second Language Writing 13, 133--151.

Hyland, K., 2005. Metadiscourse: Exploring Interaction in Writing. Continuum, London.

Hyland, K., 2007. Applying a gloss: exemplifying and reformulating in academic discourse. Applied Linguistics 28 (2), 266--285.

Hyland, K., Jiang, K., 2018. "In this paper we suggest': changing patterns of disciplinary metadiscourse. English for Specific Purposes. 51, 18--30.

Hyland, K., Jiang, K., 2019. “Points of reference: changing patterns of academic citation'. Applied Linguistics 40 (1), 64--85.

Hyland, K., Tse, P., 2005. Evaluative that constructions: signalling stance in research abstracts. Functions of Language 12 (1), 39--64.

Jiang, F.K., 2017. Metadiscursive Nouns in Disciplinary Writing The University of Hong Kong (Unpublished PhD Thesis).

Jiang, K., Hyland, K., 2015. "The fact that': Stance nouns in disciplinary writing. Discourse Studies $17 \quad$ (5), 529--550. http://dx.doi.org/10.1177/ 1461445615590719

Jiang, K., Hyland, K., 2016. Nouns and academic interactions: a neglected feature of metadiscourse. Applied Linguistics 39 (4), 508--531. Kolln, M., \& Gray, L. 
(2010). Rhetorical grammar: Grammatical choices, rhetorical effects. Boston: Longman.

Kwan, B. S. C., Chan, H., \& Lam, C. (2012). Evaluating prior scholarship in literature reviews of research articles: A comparative study of practices in two research paradigms. English for Specific Purposes, 31(3), 188-201.

Lambrecht, K. (1994). Information structure and sentence form: Topic, focus, and the mental representations of discourse referents. Cambridge Cambridge University Press.

Lannon, J. M. (2006). Technical communication (10th ed.). London: Longman.

Leggett, G., Mead, C. D. \& Charvat, W. (1978). Prentice-Hall handbook for writers. Englewood Cliffs, NJ: Prentice-Hall.

Martínez Insua, A. E. (2004). Existential there-constructions in contemporary British English: A corpus driven analysis of their use in speech and writing. München: Lincom.

MAXQDAplus. (2012) (Version 11) [Computer software]. Berlin, Germany: VERBI $\mathrm{GmbH}$.

Mur-Dueñas, P. (2011). An intercultural analysis of metadiscourse features in research articles written in English and in Spanish. Journal of Pragmatics, 43(12), 3068-3079.

Palacios-Martínez, I., \& Martínez-Insua, A. (2006). Connecting linguistic description and language teaching: Native and learner use of existential there. International Journal of Applied Linguistics, 16(2), 213-231.

Quirk, R., Crystal, D., Leech, G., \& Svartvik, J. (1985). A comprehensive grammar of the English language. Harlow: Longman.

Schmid, H.-J. (2000). English abstract nouns as conceptual shells: From corpus to cognition. Berlin: Walter de Gruyter.

Seoane, E. (2013). On the conventionalisation and loss of pragmatic function of the passive in Late Modern English scientific discourse. Journal of Historical Pragmatics, 14(1), 70-99.

Swales, J. M. (1990). Genre analysis: English in academic and research settings. Cambridge: Cambridge University Press.

Tadros, A. (1985). Prediction in text. Birmingham: English Language Research, University of Birmingham.

Thompson, G. (2014). Introducing functional grammar (3rd ed.). London: Routledge. 


\section{Appendix 1 Journal list}

\section{(1) Applied Linguistics}

Applied Linguistics

TESOL Quarterly

Second Language Research

System

English for Specific Purposes

Journal of English for Academic Purposes

\section{(2) Sociology}

American Journal of Sociology

The Sociological Review

Current Sociology

International Journal of Comparative

Sociology

Sociology

\section{(3) Electronic Engineering}

International Journal of Microwave and

Millimeter-Wave CAE

Microsystem Technologies

IEEE Transactions on Microwave Theory

and Techniques

Journal of Microelectromechanical

Systems

Solid-state Electronics

Microelectronics Journal

\section{(4) Biology}

Journal of Cell Biology
Journal of Second Language Writing

Journal of Pragmatics

Written Communication

International Journal of Applied

Linguistics

International Sociology

British Journal of Sociology

British Journal of Criminology

Criminology

International Journal of the Sociology of

Law

Analog Integrated Circuits and Signal

Processing

Journal of Manufacturing Science and

Engineering

International Journal of Production

Research

International Journal of Industrial

Engineering

Mycological Research 
The Plant Cell

Plant Molecular Biology

Plant, Cell and Environment

Molecular and Cellular Biology
Mycologia

New Phytologists

Canadian Journal of Botany

Plant Physiology

\section{Appendix 2 Coding scheme}

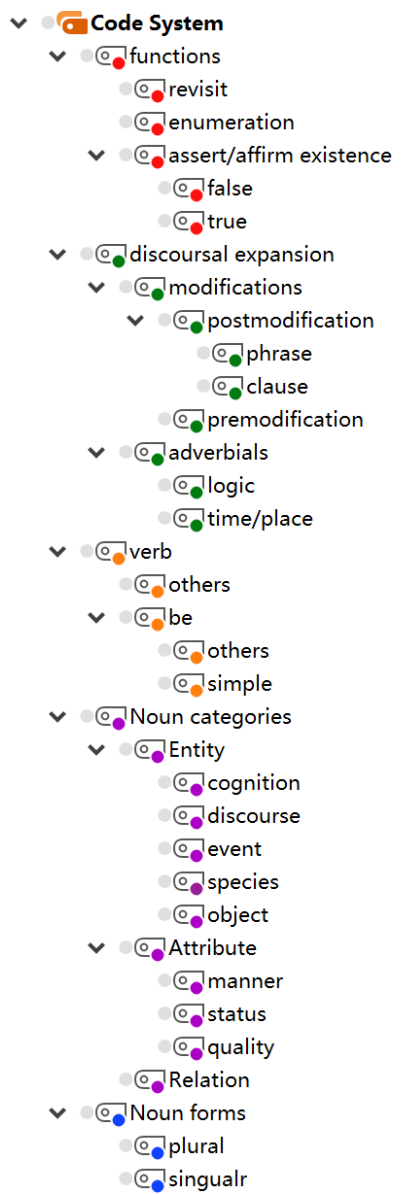

